NBSIR 84-2883

\title{
Characterization of Porosity in Porous Polymer Implant Materials
}

R. E. Dehl

U.S. DEPARTMENT OF COMMERCE

National Bureau of Standards

Dental and Medical Materials

Polymers Division

Gaithersburg, MD 20899

February 1984

Issued September 1984

Annual Report for period April through September 1983

\section{Prepared for:}

\section{Office of Medical Devices}

Center for Devices and Radiological Health ring, MD 20910 



\section{CHARACTERIZATION OF POROSITY IN POROUS POLYMER IMPLANT MATERIALS \\ YMER IMPLANT MATERIALS}

A

R. E. DehI

U.S. DEPARTMENT OF COMMERCE

National Bureau of Standards

Dental and Medical Materials

Polymers Division

Gaithersburg, MD 20899

February 1984

Issued September 1984

Annual Report for period April through September 1983

Prepared for:

Office of Medical Devices

National Center for Devices and Radiological Health

Food and Drug Administration

Silver Spring, MD 20910

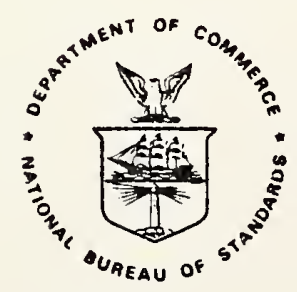

U.S. DEPARTMENT OF COMMERCE, Malcolm Baldrige, Secretary NATIONAL BUREAU OF STANDARDS, Ernest Ambler, Director 


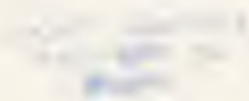




\section{TABLE OF CONTENTS}

Page

ANNOUNCEMENT

iv

ABSTRACT . . . . . . . . . . . . . . . . . . . v v

I. INTRODUCTION . . . . . . . . . . . . . . . . . 1

II. QUANTITATIVE MICROSCOPY . . . . . . . . . . . . . . 2

A. Preparation of PTFE-C for Photomicrography . . . . . . 3

B. Results and Discussion . . . . . . . . . . . . 3

1. Void Volume .. . . . . . . . . . 5

2. Mean Intercept Length ... . . . . . . . . 6

III. MERCURY POROSIMETRY . . . . . . . . . . . . . . . . . 9

A. Instrumentation ................ . 9

B. Experimental Errors............... 11

C. Materials................ . . 12

D. Results................. 12

E. Discussion ................ . . 18

IV. SUMMARY . . . . . . . . . . . . . . . . . . . . 21

REFERENCES . . . . . . . . . . . . . . . . . . 23 
FIGURES

Page

Fig. 1. Photomicrograph of cross-section of polished, resin-filled PTFE-C composite.................. 4

Fig. 2. Macro-filling accessory with penetrometer . . . . . 10

Fig. 3. Outline of 16 pressure-volume curves obtained for PTFE-C in sheet form ............ 14

Fig. 4. Outline of 6 pressure-volume curves obtained for PTFE-C in laminated block form ........ 15

ii 


\section{TABLES}

Page

Table I. Porosity Parameters from Quantitative

Microscopy . . . . . . . . . . . 7

Table II. Four Parameters Obtained from Mercury

Intrusion Curves for 16 Samples of

PTFE-C Sheet and 6 Samples of Block ...... 17

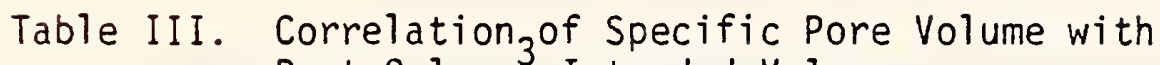

$P$ at $0.1 \mathrm{~cm}^{3}$ Intruded Volume ........ 20 


\section{ANNOUNCEMENT}

Certain commercial materials and suppliers are identified in this report in order to adequately specify experimental procedures. In no case does such identification imply recommendation or endorsement by the National Bureau of Standards, nor does it imply that the identified materials or suppliers are necessarily the best available. 


\section{ABSTRACT}

Our investigation of the methods of characterizing the porosity of two porous polymeric implant materials have been concluded with the work discussed in this report. The two materials, a porous polyethylene (PPE) and a porous composite of polytetrafluoroethylene and carbon (PTFE-C) have been further investigated by the method of quantitative microscopy. The mean pore volume fractions of 30 samples each of PPE and PTFE-C were found to be 0.48 and 0.69 , respectively, and are in good agreement with other measurements of this quantity. The mean intercept length for PPE was found to be $76 \mu \mathrm{m}$, and for PTFE-C, $67 \mu \mathrm{m}$. Both values are somewhat larger than the average interconnecting pore "diameters" as measured by mercury porosimetry. The reproducibility of mercury porosimetry data has been tested by examining 16 samples of PTFE-C in thin sheet form and 6 samples of laminated blocks. The mean and standard deviation of four parameters derived from the mercury intrusion curves were calculated. A high correlation was found between the specific pore volume and the position of the mercury intrusion curve along the pressure axis. A number of random errors pertaining to mercury porosimetry were discovered and are discussed in this report. 


\section{INTRODUCTION}

Our previous investigations of the characterization of porosity in two commercially available porous polymeric implant materials have been reported in three Annual Reports to the Office of Medical Devices (FDA) ${ }^{1-3}$. The materials are a porous polyethylene (PPE) and a porous composite of polytetrafluoroethylene and carbon (PTFE-C). Following these studies, a proposal was written to continue the investigation of these materials, including three tasks which we felt were necessary to bring these studies to a successful conclusion. The specified tasks were:

(1) to continue the investigation of pore size and pore volume in PPE by the method of quantitative microscopy, until a statistically significant sampling was achieved, and to perform the same number of measurements on the composite material. The results of these studies would be compared with those obtained by other techniques such as mercury porosimetry.

(2) to obtain a statistically significant number of mercury intrusion curves for one of the materials and to analyze the data to determine several parameters related to porosity. It was proposed that the composite material in sheet form would be most suitable for these measurements.

(3) to attempt to determine whether a real difference exists between the porosity of the composite material in sheet form and in the form of laminated blocks. 
Task 1 has been successfully completed and the results are discussed in Section II. Tasks 2 and 3 have also been concluded, al though the number of samples examined was not as large as originally anticipated, due to restricted available time, instrumental difficulties, and the inability to find a current supplier of the laminated composite. Nevertheless, it is concluded that these studies have produced a significant insight into the various methodologies for characterizing porosity.

\section{QUANTITATIVE MICROSCOPY}

The theoretical background for the analysis of pore size and pore volume by quantitative microscopy (stereology) was discussed in our last Annual Report ${ }^{3}$. Measurements were made by means of a $6 \times 4$ line transparent test grid laid on a photomicrograph of a polished cross-section of the porous material. The latter (PPE) was filled with a hard resin to facilitate grinding and polishing. Two parameters were determined from the test grid analysis, namely (1) the pore volume fraction $P_{p}$, which is the fraction of line intersections or "points" falling within the desired (pore) phase region, and (2) the mean intercept length $\bar{L}$, which is defined as the point fraction $P_{B}$ divided by $N_{L}$, the number of chords traversing the desired (pore) phase region per unit of test length. $[$ is a measure of the pore "size". It was chosen arbitrarily; other parameters related to pore size could equally well have been measured, but $\bar{L}$ is probably the easiest to measure by manual methods, and it appears to be relatively free from operator bias.

The surface of the polished PPE was found to be quite inhomogeneous on the dimensional scale of the areas sampled in the photomicrographs, as evidenced by a wide scatter in the experimental results. For this reason, 
it was decided that a relatively large number of samples should be examined, in order to estimate the population mean and standard deviation. Ten additional photographs of the same specimen examined previously were analyzed, for a total of 30 . Thirty photomicrographs of one specimen of the composite material were also obtained. The results are reported below. A. Preparation of PTFE-C for Photomicrography Preparation of the composite material in laminated block form for optical analysis proved to be somewhat more difficult than the preparation of PPE, because the liquid resin ${ }^{4}$ used to fill the pores did not spontaneously flow into the material. In order to fill a sample with resin, it was necessary first to submerge it with a lead weight into the liquid resin + initiator, contained in a vacuum flask attached to a pump. Pumping was continued until no further air bubbles were seen emerging from the sample. Admission of air forced the liquid into the pores. The sample was removed from the liquid resin and cured at $70^{\circ} \mathrm{C}$ overnight $(15-20 \mathrm{~h})$. The cooled sample was ground flat with 600 grit carborundum paper, followed by a final polishing with $0.05 \mu \mathrm{m}$ alumina powder. Unlike the PPE, it was not found necessary to dye the clear resin in order to obtain adequate visual phase contrast. A sample prepared with dyed resin looked the same under the microscope as one prepared with clear resin. A typical photomicrograph of this material is shown in Fig. 1. The small white spots are the highly reflective carbon particles. The dark gray streaks are the PTFE fibers, and the medium gray regions are the filled pores.

B. Results and Discussion

The results of thirty photomicrographic analyses for each of the porous materials are shown in Table 1. Each set of photographs was taken on one 


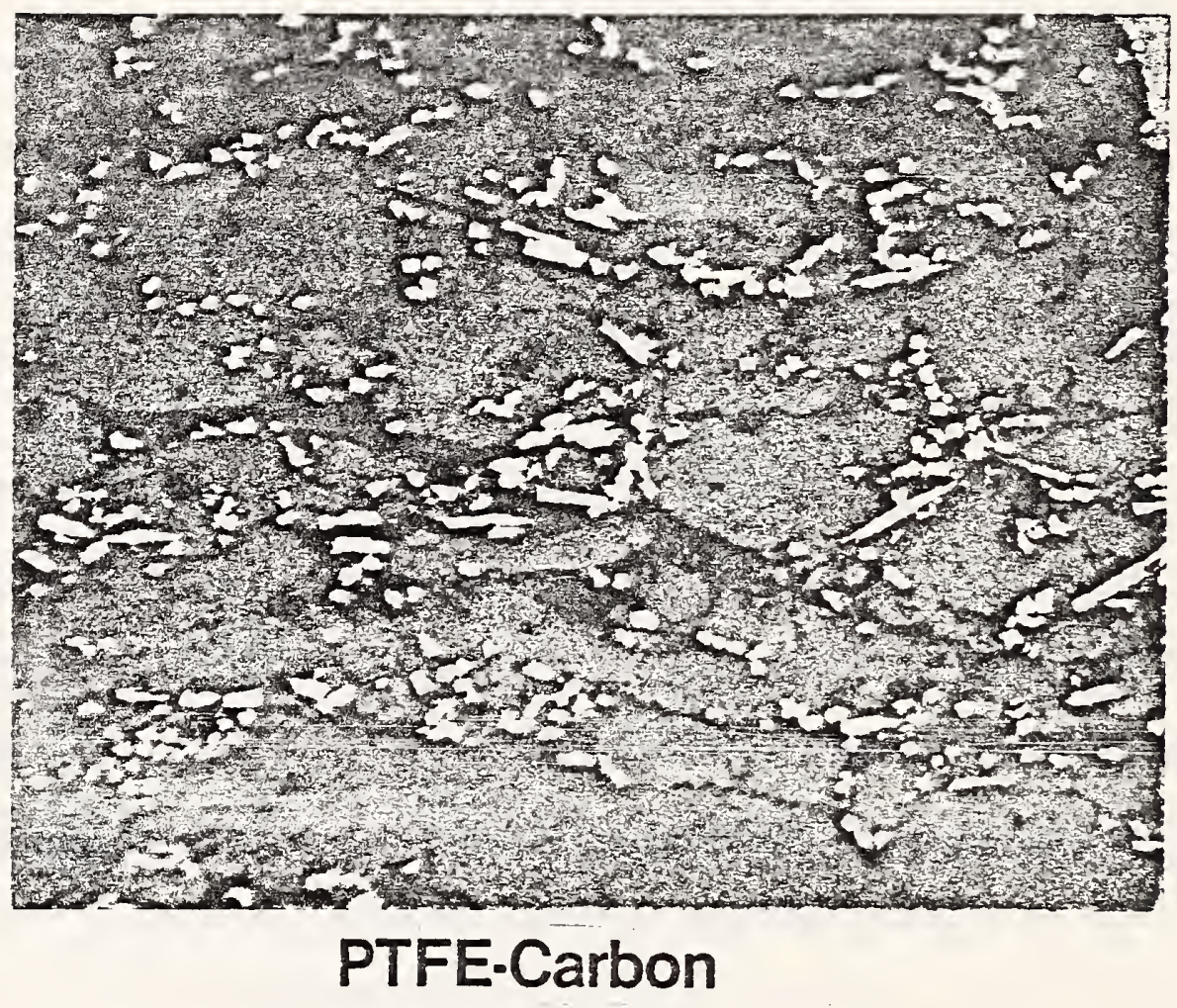

Fig. 1. Photomicrograph of cross-section of polished, resin-filled PTFE-C composite (180 X). 
sample of material, by moving the overhead light beam randomly about on the surface. All of the pictures were used; none was discarded because it appeared less "typical" than average.

1. Void Volume

The void volume fraction of PPE reported in Table I is slightly larger than that found by two other methods. ${ }^{2}$ However, the difference between the value obtained by this method and the others is well within one standard deviation from the mean, indicating that the difference between them may not be statistically significant.

The pore volume fraction in PTFE-C is within the range (67, to $70 \%$ ) found by three other methods ${ }^{2}$, and one might therefore conclude that there is a high probability that the true value lies within this range. However, a question about the density of solids in the composite material remains unresolved. The apparent density method depends upon a knowledge of these densities, which were measured by "quantitative" expulsion of air in an hydraulic press, followed by a measurement of the density of a cylindrical disc cut out of the compressed sample. The density found in this way $\left(1.4 \mathrm{~g} / \mathrm{cm}^{3}\right)$ is less than the published densities of both components. The density of pyrolytic carbon is reported ${ }^{5}$ to be from 1.5 to $2.0 \mathrm{~g} / \mathrm{cm}^{3}$. The density of PTFE is reported ${ }^{6}$ to be $2.3 \mathrm{~g} / \mathrm{cm}^{3}$. From an elemental analysis of the composite, we have determined ${ }^{2}$ that the material is $62 \%$ PTFE and $38 \%$ carbon, by weight. Using the minimum density reported for carbon, we find that the density of total solids $\left(d_{s}\right)$ is at least 


$$
\begin{aligned}
d_{s} & =0.62(2.3)+0.38(1.5) \\
& =2.0 \mathrm{~g} / \mathrm{cm}^{3}
\end{aligned}
$$

Using this value for the density of solids in the porous material, we find that the pore volume would be $79 \%$. This value is only one standard deviation from the mean optical microscopic value reported in Table I, so that a pore volume of $79 \%$ cannot be excluded.

There is evidence that two of the methods which we have previously discussed $^{2}$ for measuring pore volume (apparent density and mercury intrusion) are higher precision measurements than the optical method and would therefore require fewer samples to estimate the population mean. Both mercury intrusion and the optical method are "absolute" in the sense that they do not require assumptions about density of solids or other variables. Mercury intrusion, however, as discussed in Section III, is subject to a number of spurious problems which could affect its accuracy in any given measurement. Clearly, if an accurate estimate of pore volume is desired, one must be prepared to do a thorough error analysis of the method selected, and preferabiy to cross-check this method with at least one other.

\section{Mean Intercept Length}

The average pore "size" defined as the mean intercept length was found to be slightly less for the PTFE-C composite than for PPE as shown in Table I. The difference between the mean values, however, is well within one standard deviation for each sample of 30 , and one would therefore not be justified in reporting a significant difference between the mean values. In order to establish whether there is a statistically significant 
difference between the two means, it would be necessary to examine a great many more samples from the same lot of material. Such an effort would not appear to be justified unless one were asking a very specific question about the materials, e.g., whether there was a real difference between the average porosity in two or more lots of material.

Table I. Porosity Parameters from Quantitative Microscopy Pore Volume Fraction $\left(P_{P}\right)$

\begin{tabular}{|c|c|c|c|c|c|}
\hline & Mean (of 30) & SD & SD/Mean & High & Low \\
\hline PPE & 0.48 & 0.09 & 0.19 & 0.67 & 0.29 \\
\hline PTFE-C & 0.69 & 0.10 & 0.14 & 0.88 & 0.38 \\
\hline
\end{tabular}

Mean Intercept Length ( $\mathrm{um}$ )

Mean(of 30)

76

67
$\underline{S D}$

17

$\underline{\text { SD/Mean }}$

0.22

14

0.21

0.21

High

Low

102

44

PTFE-C

(14)

115

42

It is interesting that the mean intercept lengths of both materials are substantialiy greater than the "interconnecting" pore diameters determined by mercury porosimetry ${ }^{2}$ ( $30 \mu \mathrm{m}$ for PPE and $50 \mu \mathrm{m}$ for PTFE-C). This observation is at least qualitatively in accord with the expectation that the average interconnecting pore "diameter" should be smaller than the overall average "diameter" of all pores in the material. However, the greatiy different pore morphologies in the two materiais preclude an exact comparison of the pore "size" as measured by two or more different 
methods. We observe that mercury porosimetry finds the average interconnecting "diameter" in PPE to be significantly less than in PTFE-C, whereas optical microscopy finds the mean intercept lengths about the same, and the hybrid method of specific surface area + pore volume ${ }^{2}$ finds the PPE to have at least twice the average pore "diameter" of the PTFE-C. Not only does the average pore "diameter" of a given material depend upon how one measures it, but the ratio of "diameters" in two different materials is seen to vary with the measurement technique.

A significant difference between the photomicrographic crosssections of PPE and PTFE-C is the presence of a great many fine particles in the latter material. These particles, which contribute little to the total volume of material, nevertheless become boundaries between phases in the measurement of mean intercept length by quantitative microscopy. A sma11 particle of carbon or PTFE in a pore divides the pore in two, for purpose of counting intercepts, if a grid line happens to intersect it. In most cases, the pore is not actually divided by the presence of a small particle, and this paradox will tend to make the measured average intercept length or pore "diameter" smaller than it appears to an intruding liquid or solid particle. This dilemma was recognized early in the optical analysis of the composite material. However, it was decided that any attempt to correct for it by purposely ignoring small particles would lead to a subjective judgment about which particles to ignore, thereby defeating the overall purpose of selecting methods of measurement which are as free from operator bias as possible. It should be noted also that the small particle effect discussed above does not distort the measurement of the pore volume fraction $P_{P}$. 


\section{MERCURY POROSIMETRY}

The theoretical basis for mercury porosimetry, as well as the errors inherent in this method and various methods for displaying the data, have been discussed in previous Annual Reports ${ }^{2,3}$. It is the purpose of the present report to continue a discussion of random errors which can occur, and to perform some statistical analyses of the data obtained from a larger sampling of the material than previously reported.

\section{A. Instrumentation}

A11 measurements were performed using a "Macro Filling" accessory for the mercury porosimeter, obtained from Superpressure, Inc. ${ }^{7} \mathrm{~A}$ picture of the assembled device is shown in Fig. 2. A porous sample is placed in the large end of the glass dilatometer ("penetrometer") and a vacuum end seal is made by means of a circular metal plate pressing against a ground glass flange on the end of the penetrometer. The latter is inserted into the glass chamber containing mercury and the "cap" forces an o-ring around the penetrometer to seal against the chamber wall, making the entire device vacuum-tight. As indicated on the figure, a rubber hose connects to a vacuum line consisting of a thermocouple vacuum gauge, a 0 to $0.1 \mathrm{MPa}$ (0 to $15 \mathrm{psia}$ ) pressure gauge, and a vacuum pump with a cold trap. A residual air pressure of $5.3 \mathrm{~Pa}(40 \mu \mathrm{m}$ of mercury) or less was achieved before filling the penetrometer with mercury.

In order to fill the penetrometer, the cradle to which it is attached is first rotated about its horizontal axis, covering the penetrometer with mercury. The device is disconnected from the vacuum pump, and a smalt air pressure $(<0.005 \mathrm{MPa})$ is admitted through the glass stopcock, filling 


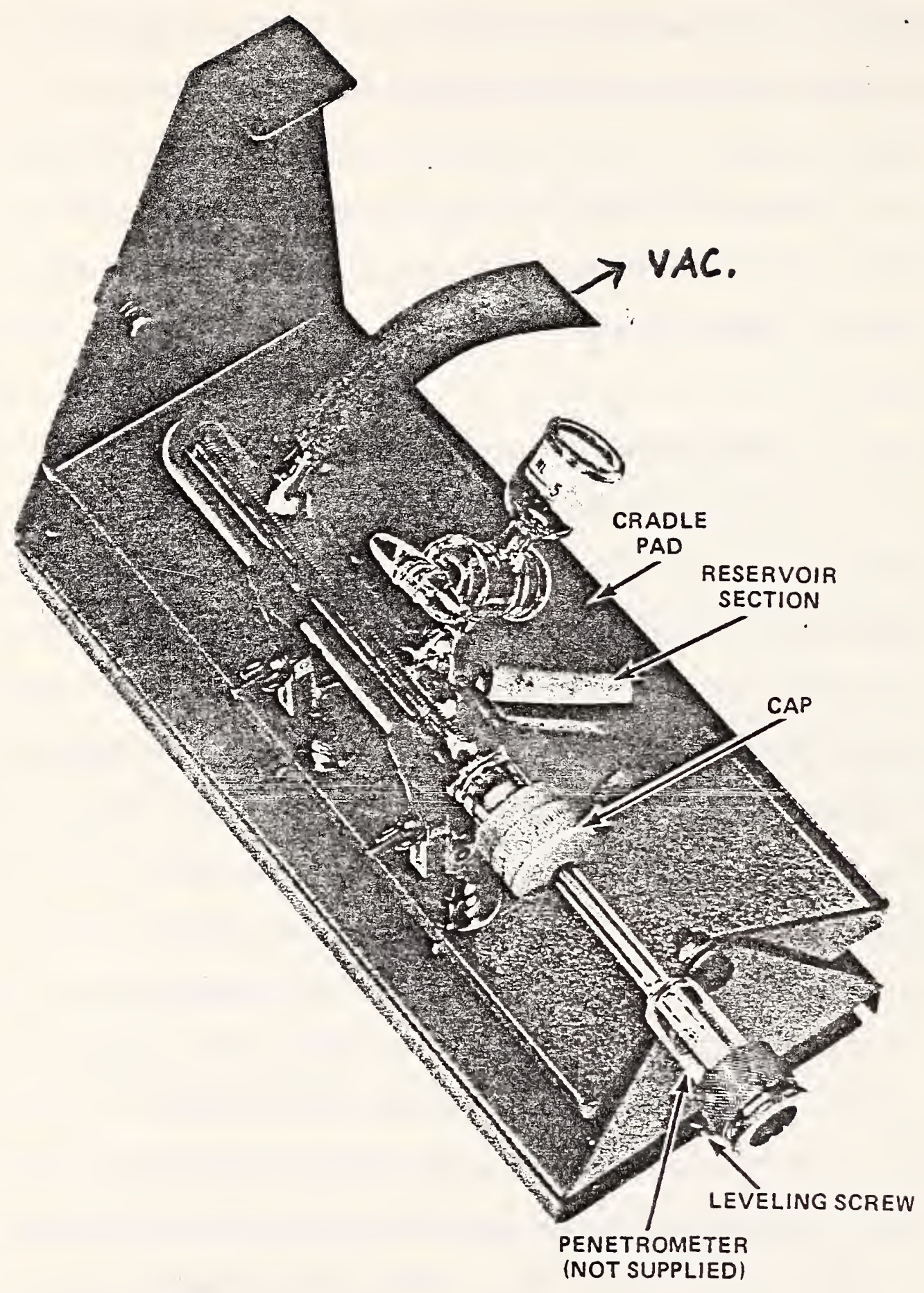

Fig. 2. Macro-filling accessory with penetrometer. 
the penetrometer with mercury. At this point, the cradle is rotated back to its original position as shown in $\mathrm{Fig} .2$, and the mercury intrusion experiment is begun. The first admitted air pressure was typically about 1.2 psia, and increments of about 1 psia were admitted, until atmospheric pressure was achieved. The penetrometer stem has a total calibrated volume of $0.2 \mathrm{~cm}^{3}$, and the volume can be estimated to $\pm 0.001 \mathrm{~cm}^{3}$. The penetrometer was removed and cleaned after each intrusion experiment.

\section{B. Experimental Errors}

Although the experiment is simple, it was found to be subject to a number of random errors, in addition to those discussed in our last Annual Report ${ }^{3}$. The pressure gauge was not accurate at very low pressures, which made it difficult to fill the penetrometer using the minimum possible pressure to avoid filling large pores, before the instrusion experiment was begun. Occasionaliy, an air bubble would appear at the top of the sample chamber after filling the penetrometer with mercury. In such cases, the first increment of pressure resulted in an unusualiy large intruded volume. In some cases the error was recognized and the run was discarded. However, in other cases, small hidden air bubbles may have been present but not observed, leading to variability in the initial penetrometer reading. The air bubbles were at first thought to be due to a leak in the penetrometer and seal. However, a vacuum leak would be expected to increase the bubble volume in time, and this was never observed. Most likely, the bubbles were due to air trapped in the mercury reservoir, and after this was recognized care was taken to evacuate the mercury chamber each time by rocking the cradle a few times to expose all surfaces to the vacuum line. 
Sometimes, after filling the penetrometer with mercury and returning the cradle to its resting position, the fnitial reading indicated a positive intruded volume. The source of this effect was not clear; it might have been due either to a small pressure surge from the chamber or to the mercury thread "breaking" at some point above the zero mark when the penetrometer was separated from the mercury pool. Fortunately, these initial non-zero readings were usually a small fraction of the total intruded volume, but they did create another source of random errors difficult to treat in the data analysis.

\section{Materials}

A11 experiments were performed on the PTFE-C material. Twenty samples in the form of thin sheets were procured ${ }^{8} ;$ all were from the same lot (HI4K) of material. The samples were individually packaged and all were nominal1y $15 \times 15 \times 1 \mathrm{~m}^{3}$ in size. The weights ranged from $0.0683 \mathrm{~g}$ to $0.0917 \mathrm{~g}$, with a mean value of $0.0801 \mathrm{~g}$. Four of the 20 mercury intrusion runs were discarded because one or more of the problems discussed above were clearly observed.

Six samples of the laminated block were studied; each was cut from the same oval block (Lot \#C24H), $6 \mathrm{~mm}$ thick. Further samples of the block composite could not be obtained from the supplier. The samples ranged in weight from $0.0742 \mathrm{~g}$. to $0.1007 \mathrm{~g}$. All six sample runs are reported here, even though in three of the cases the initial (zero) penetrometer reading equalled or exceeded $0.01 \mathrm{~cm}^{3}$.

D. Results

In each mercury intrusion experiment, approximately 15 pressurevolume readings were obtained at intervals of $\Delta P \cong 1$ psi, and a smooth 
curve was drawn through them. All curves were normalized to the same end point $\left(V=0.21 \mathrm{~cm}^{3}\right)$ by multiplying each measured volume increment by the appropriate constant factor. Fig. 3 is an outline of the extreme deviations of all $16 \mathrm{P}-\mathrm{V}$ curves, for the composite sheet samples. All of the curves fall within these boundaries, with the majority falling in a rather narrow band near the center of the outlined zone. Fig. 4 is the corresponding outline for the six block sample curves. The pore "diameters" on the lower $x$-axis were calculated from the Washburn equation ${ }^{2}$, using the formula $D=\frac{232}{P}$, where $D$ and $P$ represent the interconnecting pore diameter and applied pressure, and the constants for the composite are gathered in the numerical term. Fig. 3 is an outline of the extreme deviations It was found by superimposing the two sets of curves that the steep portions of the curves for the block samples lie to the right side of most of the curves for the sheet samples. A shift to the right (higher pressure) corresponds to a smaller average pore size, so that this observation is at least qualitatively in accord with the expectation that the interconnecting pores in block samples may, on the average, be somewhat smalier than those in sheet samples. This question is discussed below at more length.

In order to make some numerical comparisons of the various P-V curves, four parameters were selected for analysis. These four were selected arbitrarily, but all together they provide some insight into the variability of mercury porosimetry data. It should be emphasized that there is no way of knowing how much scatter in the data is due to sample variability and how much to instrumental randomerrors, which have been discussed above. 


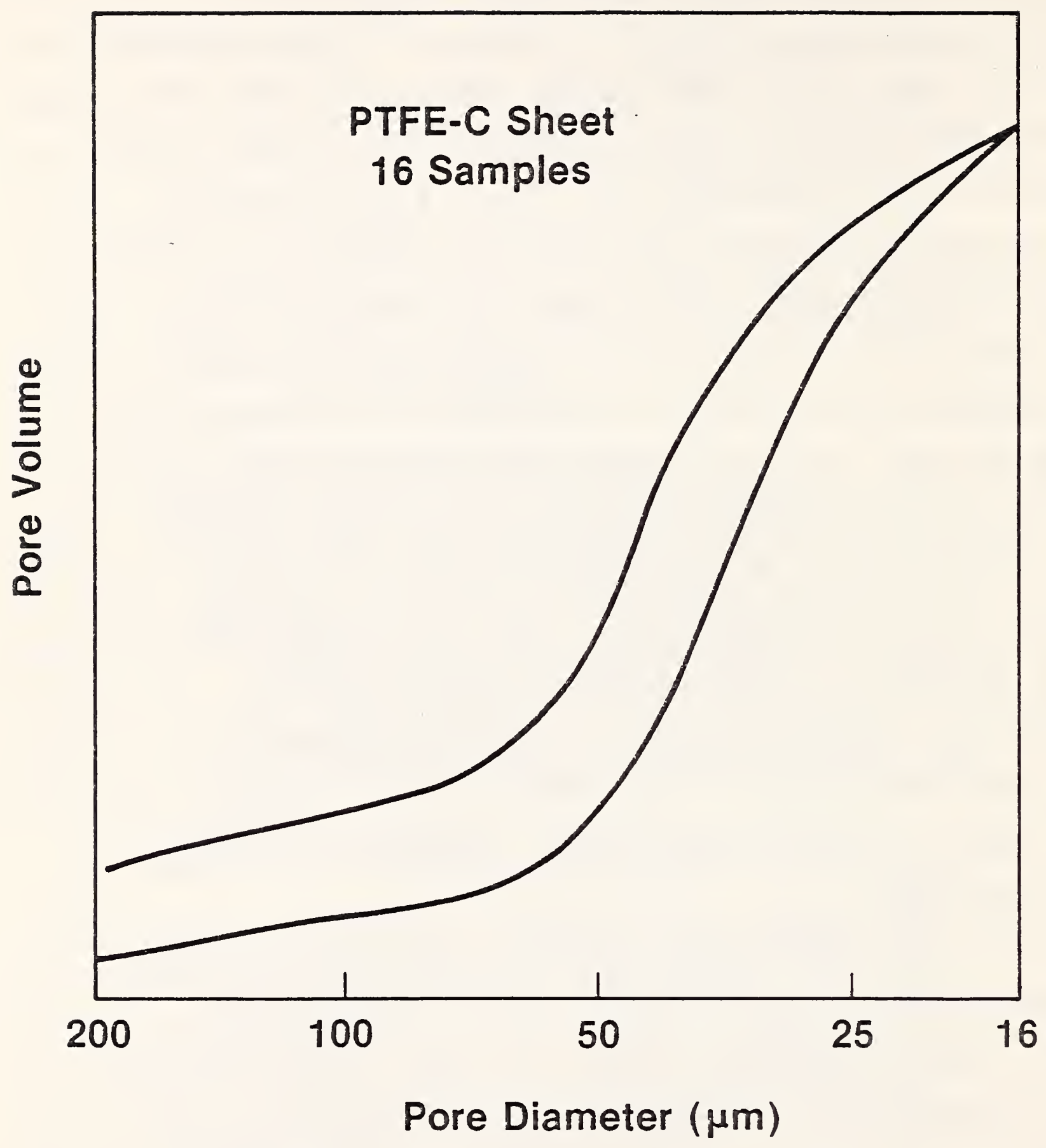

Fig. 3. Outiine of 16 pressure-volume curves obtained for PTFE-C in sheet form. 


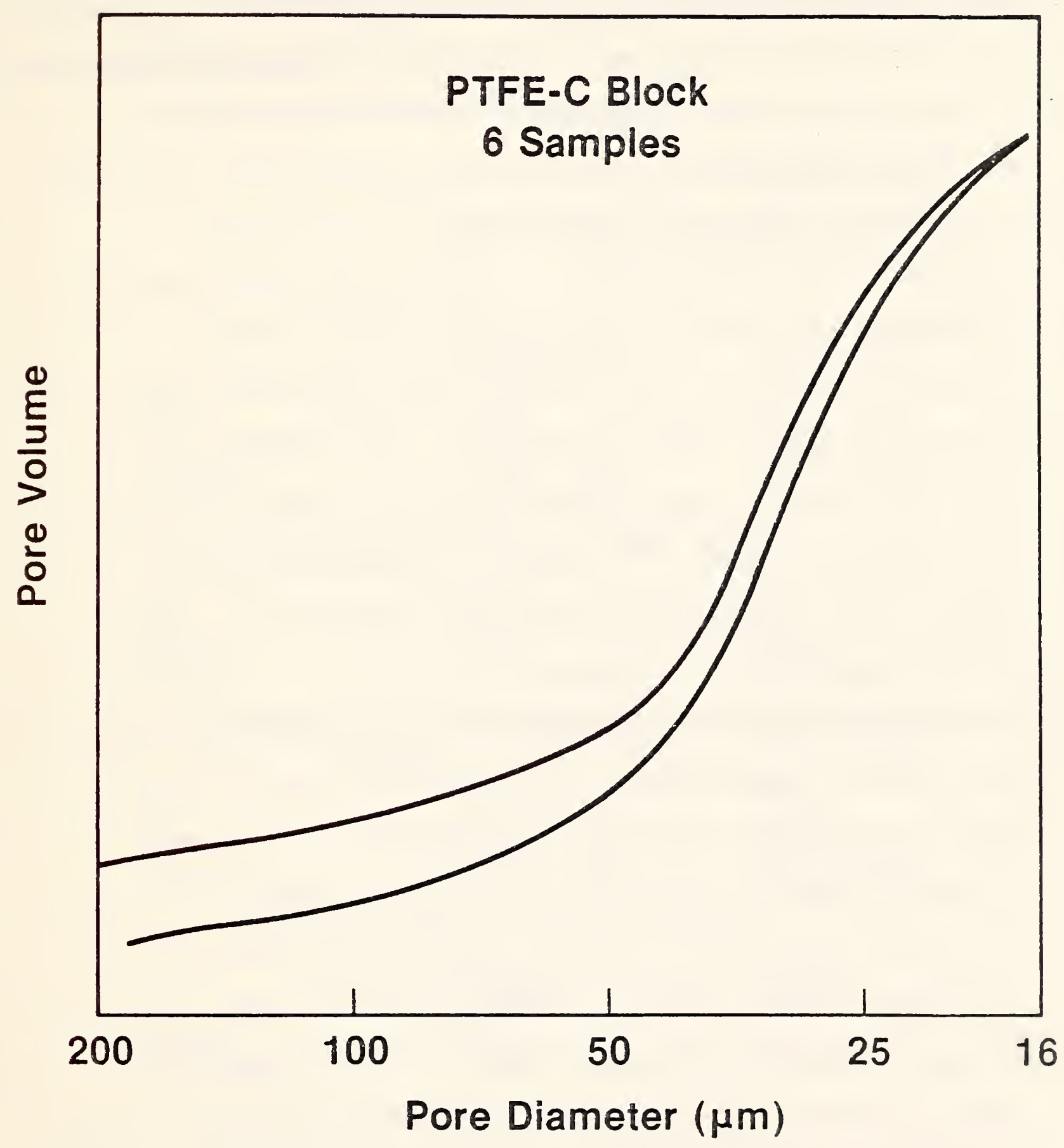

Fig. 4. Outline of 6 pressure-volume curves obtained for PTFE-C in laminated block form. 
If it were possible to make replicate measurements on the same sample, one might be able to separate instrumental errors from sample variations. However, it is impossible to extrude mercury quantitatively from the porous material, so that a second intrusion experiment would be different from the first one in some unknown way.

The four quantities selected for analysis were:

(1) the specific pore volume $\left(\mathrm{cm}^{3} / \mathrm{g}\right)$.

(2) the pressure corresponding to one selected volume of pores filled with mercury $\left(0.1 \mathrm{~cm}^{3}\right.$, end-point normalized curves).

(3) the fraction of pore volume corresponding to one selected interval of pressure. The interval between $P=4$ psia and $P=8$ psia was selected. This interval corresponds to about half the total intruded pore volume and is equivalent to a pore size range from 29 to $58 \mu \mathrm{m}$.

(4) the volume of pores filled with mercury at 1.2 psia pressure. This pressure is approximately that at which the first P-V point was recorded in each intrusion experiment. It corresponds to a pore "diameter" of $193 \mu \mathrm{m}$, so that the pore volume filled with mercury at this pressure should be that of afl interconnecting pores having a diameter greater than about $200 \mu \mathrm{m}$. As discussed above, low pressure data are subject to a number of random errors, and the data recorded at 1.2 psia reflect this scatter as well as possible variations in the samples. 
The results of these analyses for 16 samples of the composite sheet and six samples of the laminated block are given in Table II. All curves were normalized to the same end point.

Table II. Four Parameters Obtained from Mercury Intrusion Curves For 16 Samples of PTFE-C Sheets and 6 Samples of Block

1. Specific Pore Volume $\left(\mathrm{cm}^{3} / \mathrm{g}\right)$

$\begin{array}{lll} & \text { Sheet (16) } & \text { Block }(6) \\ \text { Mean } & 1.57 & 1.56 \\ \text { SD } & 0.09 & 0.05 \\ \text { SD/Mean } & 0.06 & 0.03 \\ \text { High-Low } & 1.69-1.41 & 1.63-1.48\end{array}$

2. Pressure at $0.1 \mathrm{~cm}^{3}$ Intruded Pore Volume (psia)
Mean
SD
5.6
6.5
SD/Mean
0.4
0.2
High-Low
0.07
0.03
$6.4-4.8$
$6.9-6.2$

3. Fraction of Pore Volume Filled Between $P=4$ and $P=8$ psia
Mean
0.51
SD
0.03
0.43
SD/Mean
0.06
0.05
High-Low
$0.56-0.46$
0.12
$0.50-0.38$

4. Volume of Pores filled at $P=1.2$ psia $\left(\mathrm{cm}^{3}\right)$
Mean
SD
0.018
0.026
SD/Mean
0.006
High-Low
0.33
$0.033-0.009$
0.008
0.31
$0.038-0.016$ 


\section{E. Discussion}

Because the number of laminated block samples is much smaller than the number of sheets, it is difficult to make quantitative comparisons between the two forms of the composite material. However, certain generalities appear to be justified even from this small sampling of what presumably is a very much larger possible number of samples in each lot of material. There is apparently no significant difference in the specific pore volume between block and sheet composite, and the differences, if any, between the two forms with respect to properties 2,3 , and 4 are sma 71 . For example, the total range of values of property 2 for the composite in sheet form is greater than the difference between the mean values for block and sheet, and it includes the mean of the block samples. For property 3 , the mean value for the block samples lies just outside the total range for the sheet samples. For property 4 , the data are widely scattered for both sets of curves. It is doubtful that this scatter truly represents differences in the volume fraction of very large pores, because of the instrumental effects discussed above. Mercury porosimetry is not capable of accurately measuring the size of very large pores.

In our second Annual Report (Ref. 2, p. 19), we presented a graph showing the effect of sample compression on a mercury intrusion curve for the composite material. As a sample is compressed, the specific pore volume decreases, and the intrusion curve is shifted to the right. The pore size distribution obtained from such curves 
is also shifted toward smaller average pore sizes than for the uncompressed matertal. This is hardly surprising, since we know how the samples were treated to produce this result. We might also ask a converse question. The data of Table II indicates a range of specific pore volumes for the "asreceived" material. We might ask whether the smaller specific pore volumes are correlated with smaller average pore sizes, as evidenced by a shift of the intrusion curves to the right. It is difficult to compare these curve shifts in a quantitative way, because the various curves have somewhat different shapes. However, a rough comparison of the curve shifts can be made by comparing the specific pore volumes with parameter 2 in Table II, the pressure corresponding to $0.1 \mathrm{~cm}^{3}$ intruded pore volume, which occurs on a steep slope of the intrusion curve and is a rough measure of the overall curve position.

In Table III, the specific pore volumes of all 16 samples of sheet composite are arranged in ascending order. The corresponding $P$ at $0.1 \mathrm{~cm}^{3}$ intruded volume is shown in the second column. There is a high correlation between the two parameters. For example, the lowest three specific pore volumes correspond to the highest three values of parameter 2. Also, the lowest three values of parameter 2 correspond to numbers 11,13 , and 15 in ascending specific pore volume. A similar high correlation was found for the six samples of block composite. For a given porous material, therefore, it is apparent that the specific pore volume correlates well with the position of the mercury intrusion curve along the pressure axis. 
Table III. Correlation of Specific Pore Volume. with $P$ at $0.1 \mathrm{~cm}^{3}$ Intruded Volume, for PTFE-C

Specific Pore Volume $\left(\mathrm{cm}^{3} / \mathrm{g}\right)$ (ascending order)
Corresponding $P$ at $0.1 \mathrm{~cm}^{3}$ Intruded Volume (psia)

1.37
1.41
1.48
1.52
1.54
1.55
1.56
1.59
1.59
1.61
1.63
1.64
1.65
1.67
1.68
1.69

6.4

6.3

6.1

5.8

6.0

5.6

5.6

5.3

5.8

5.75

5.1

5.45

4.95

5.35

4.85

5.75

One may question whether the porosity at the surface of a porous material, particularly one as soft as the PTFE-C composite, is representative of the interior porosity. Certainly, it is possible to occlude surface pores in the process of cutting, packaging, and handling the material. It has been reported $^{9}$ that the tissue ingrowth process may be enhanced by "teasing" the surface before implantation in order to expand the surface pores. While this may be a useful clinical procedure, it cannot be a part of the porosity characterization process unless some way is found to treat all samples uniformly.

From the high-low values of each parameter given in Table I, it is clear that one mercury intrusion experiment may not be a very good representative of a given lot of porous material. Whenever possible, several 
replicate measurements should be made. Automated porosimeters, which are commercially available, should eliminate operator bias and reduce the effort, If not the time, expended in gathering the necessary data.

\section{SUMMARY}

The study of porosity characterization methods has been concluded with the following results:

(1) Quantitative Microscopy

Ten more photomicrographs of PPE have been analyzed, bringing the total number to 30. A sample of PTFE-C was prepared for optical analysis by filling it with a thermosetting resin and polishing a cross-section. The mean values of the pore volume fraction and mean intercept length in the two materials were compared, using 30 photomicrographs of each material. The pore volume fractions were in good agreement with the values obtained by other methods. The mean intercept lengths in PPE and PTFE-C were found to be, respectively, $76 \mu \mathrm{m}$ and $67 \mu \mathrm{m}$. The data were widely scattered, indicating that the surfaces were quite nonuniform on the dimensional scale of the areas sampled.

(2) Mercury Porosimetry

The mercury intrusion studies were concluded with the examination of 16 samples of the PTFE-C composite in sheet form and 6 samples of the laminated block. Four parameters were selected arbitrarily for statistical analysis of these data. It was concluded that little, if any, difference exists in the porosity of the sheet and block forms of this material, although the data suggest that the average pore size may be slightly smaller in the block material. A high degree of correlation was found in both 
materials between the specific pore volume and the overall position of the mercury intrusion curve along the $x$ (pressure) axis, with the smaller specific pore volumes associated with smaller average pore "diameters". It was concluded that one mercury intrusion curve may not represent a given, lot of material very well, and that several samples from a given lot should be examined. 


\section{REFERENCES}

1. Deh1, R. E., Grant, W. H., and Cassel, J. M., "Evaluation of Methods of Characterizing the Porosity of Porous Polymeric Implant Materials: A Review of the Current Status of Porosity Measurements", NBSIR 812212. Annual Report prepared for the Bureau of Medical Devices, Food and Drug Administration, Silver Spring, MD (February 1981).

2. Deht, R. E., Grant, W. H., and Cassel, J. M., "Characterization of Porosity in Porous Polymeric Implant Materials", NBSIR 81-2459. Annual Report prepared for the Bureau of Medical Devices, Food and Drug Administration, Silver Spring, MD (February 1982).

3. Dehl, R. E., "Characterization of Porosity in Porous Polymeric Implant Materials", NBSIR 83-2645. Annual Report prepared for the Office of Medical Devices, National Center for Devices and Radiological Health, Food and Drug Administration, Silver Spring, MD (February 1983).

4. Castolite TM Resin, trademark of Buehler, Ltd.

5. Bokros, J. C., La Grange, L. D., Schoen, G. J., "Chemistry and Physics of Carbon", Vol. 9, ed., P. L. Walker, Marcel Dekker, New York (1972).

6. "Polymer Handbook", eds. J. Brandrup and E. H. Immergut, Second Ed., Wiley-Interscience (New York).

7. Superpressure, Inc., Silver Spring, MD.

8. Dow Corning Wright, Inc., Memphis, TN.

9. Spector, M., Harmon, S. L., and Kreutner, A., J. Biomed. Mater. Res. 13, 677 (1979). 
NBS.11 IAA IREV. 2-BCI

\begin{tabular}{|c|c|c|}
\hline $\begin{array}{l}\text { U.S. OEF:T. OF C.MM. } \\
\text { BIBLIOGRAPHIC DATA } \\
\text { SHEET (See instructions) }\end{array}$ & $\begin{array}{l}\text { 1. PUBLICATION OR } \\
\text { REPORT NO. } \\
\text { NBSIR } 84-2883\end{array}$ & \begin{tabular}{|l|r|} 
2. Performing Organ. Report No. Publication Date \\
September 1984
\end{tabular} \\
\hline
\end{tabular}

4. TITLE AND SUBTITLE

Characterization of Porosity in Porous Polymer Implant Materials

5. $A \cup T H O R(S)$

R. E. Deh 1

6. PERFORMING ORGANIZATION (If joint or other than NBS, see instructions)

NATIONAL BUREAU OF STANDARDS

DEPARTMENT OF COMMERCE

WASHINGTON, D.C. 20234

7. Contract/Grant No.

8. Type of Report \& Period Covereo

Annual Report for the

Period April-Sept. 1983

9. SPONSORING ORGANIZATION NAME AND COMPLETE ADDRESS (Street, City, Stote, ZIP)

Office of Medical Devices

National Center for Devices and Radiological Health

Food and Drug Administration

Sitver Spring, MD

10. SUPPLEMENTARY NOTES

Document describes a computer program; SF-185, FIPS Software Summary, is attached.

11. ABSTRACT (A 200-word or less factual summary of most significant information. If document includes a significant bibliography or literature survey. mention it here)

Our investigation of the methods of characterizing the porosity of two porous polymeric implant materials have been concluded with the work discussed in this report. The two materials, a porous polyethylene (PPE) and a porous composite of polytetrafluoroethylene and carbon (PTFE-C) have been further investigated by the method of quantitative microscopy. The mean pore volume fractions of 30 samples each of PPE and PTFE-C were found to be 0.48 and 0.69 , respectively, and are in good agreement with other measurements of this quantity. The mean intercept length for PPE was found to be $76 \mu \mathrm{m}$, and for PTFE-C, $67 \mu \mathrm{m}$. Both values are somewhat larger than t'le average interconnecting pore "diameters" as measured by mercury porusimetry. The reproducibility of mercury porosimetry data has been tested by examining 16 samples of PTFE-C in thin sheet form and 6 samples of laminated blocks. The mean and standard deviation of four parameters derived from the mercury intrusion curves were calculated. A high correlation was found between the specific pore volume and the position of the mercury intrusion curve along the pressure axis. A number of random errors pertaining to mercury porosimetry were discovered and are discussed in this report.

12. KEY WORDS (Six to twelve entries; alphabetical order; capitalize only proper names; and sepurate key soros ty snm co a

Mercury porosimetry; porous implants; porous polyethylene; pore size; pore volume; PTFE-carbon composite; stereology.

13. AVAILABILITY

$\bar{X} \bar{X}$ Unlimited

$\square$ For Official Distribution. Do Not Release to NTIS

Order From Superintendent of Documents, U.S. Government Printing Office, Washington, D.C. 20402.

14. 140.05 PRI:TED PAGES 31

15. Price

XX Order From National Technical Information Service (NTIS), Springfield, VA. 2216I 


